\title{
Safety Nursing Measures for Patients Undergoing Upper Gastrointestinal Endoscopy
}

\author{
Hend Ibrahiem Metwally, Clinical Instructor \\ Medical Surgical Nursing, Faculty of Nursing, Alexandria University \\ Shadia Ahmed Abou Donia, Professor \\ Medical Surgical Nursing, Faculty of Nursing, Alexandria University \\ Thoraya Mohamed Abdel Aziz, Lecturer \\ Medical Surgical Nursing, Faculty of Nursing, Alexandria University
}

\begin{abstract}
Endoscopy services are the cornerstone of diagnosis and treatment in gastroenterology. Over the past 100 years, there has been a dramatic and explosive growth of information and technology related to the science and practice of gastroenterology. The endoscopy nurse is responsible for ensuring patient's physical safety and psychological well-being before, during and after endoscopy procedure to prevent any hazards or avoidable complications. Objective: To assess safety nursing measures applied for the patients undergoing upper Gastrointestinal (GI) endoscopy. Settings: The study was carried out at 18 gastroenterology endoscopy units, 12 units in Alexandria governorate and 6 units in Damanhour city. Subjects: Subjects comprised all nurses working in the previously mentioned settings total of 50 nurses who embraced 32 and 18 in Alexandria and Damanhour respectively. Tools: Two tools were developed to collect the necessary data; Upper (GI) Endoscopy Unit Assessment Checklist and Upper (GI) Endoscopy Safety Nursing Measures Observational Checklist. Results: A statistically significant correlation between training and performance of safety nursing measures after endoscopy was revealed. Practice of nurses' with bachelor degree illustrated higher safety measures than those with technical and secondary schools diploma before and after the upper GI endoscopy procedure. Technical nurses' illustrated higher safety measures during the procedure than the other nurses. Conclusion: It can be concluded that the highest available and adequate upper gastrointestinal endoscopy unit's physical setup structure and facilities were found in the private hospitals and clinics followed by health insurance, university and governmental hospitals respectively. Moreover, the Practice of nurses' who received pre and in-service training related to GI endoscopy procedure, illustrated more safety measures than those who didn't receive such training programs. Recommendations: It was recommended to promote gastrointestinal endoscopy unit with the necessary units' physical structure design and facilities in order to reach the optimal standard. As well; the provision of pre-service and in-service training programs for nurses working in those Upper Gastrointestinal Endoscopy units is very important to maintain safety nursing measures for patients undergoing upper gastrointestinal endoscopy.
\end{abstract}

Keywords: Safety nursing measures, Upper gastrointestinal endoscopy.

\section{Introduction}

Endoscopies have undergone significant changes inaccordance with the advances in instrumental technology. This has improved the ability to take video pictures onto the computer screen and to print them, which enabled more effective image capture, storage and retrieval as well as quality of patient's assessment ${ }^{(1)}$. 
Upper gastrointestinal (GI) endoscopy uses a lighted, flexible, fiberoptic endoscope to visualize inside the upper GI tract which is used to diagnose the cause of abdominal pain, nausea, vomiting, swallowing difficulties, gastric reflux, unexplained weight loss and allows the detection of ulcers, cancers, polyps and sites of internal bleeding ${ }^{(2,3)}$.

Upper GI endoscopy is also used in the treatment of gastrointestinal diseases in which, areas of blockage can be opened, polyps can be removed and active bleeding can be stopped. Upper GI endoscopy is easily carried out in hospital- based or on an outpatient basis as the technique is extremely safe, with very low rates of complications $^{(4,5)}$. However, unintentional harm during this invasive clinical procedure may occur as a result of care which is often delivered in a pressurized and fast-moving environment that sometimes leads to patient's death $^{(5)}$.

Endoscopic hazards can be classified into: Physical hazards: including Cardiopulmonary, sedation-related hazards, Aspiration pneumonia and bleeding due to inadequate pre procedure physical preparation for clinical history as well as lack of post procedure instructions at the first $24 \mathrm{hrs}$. In addition to chemical hazards: including improper endoscope rinsing from chemical disinfectant agents, biological hazards: comprising the risk of transmission of bacterial infection from patient to patient and patient to staff due to ignorance of the recommended infection control precaution, psychological hazards: result from improper procedures instructions explanation ${ }^{(6,7)}$. Therefore the referring clinician, endoscopist and endoscopy nurse shouldn't consider such procedures as routine in order to avoid the risk and consequences that may occur ${ }^{(6,7)}$.

Patient safety is a patient's freedom from unnecessary or potential harm associated with healthcare ${ }^{(8)}$. All nurses have a significant contribution to protect and improve the high-quality and safe endoscopy procedure, so that diagnoses are made or excluded, and/or therapy is properly performed with minimum risk $^{(9)}$.

The endoscopy unit design should fits the international standards of patient safety and infection control, in addition to instilling comfort and security for both the endoscopy staff and the patient. The endoscopy unit should have a smart public face that includes waiting and reception area as well as preparation, procedure, recovery, cleaning, maintenance and storage of equipment, reporting and archiving, and staff management areas, and a more functional back hall ${ }^{(10)}$.

Endoscopy nursing has been developed as a discipline with a highly qualified nurses working alongside the endoscopist $^{(11)}$. Safety nursing measures should be considered in three time periods before, during and after endoscopy procedure to prevent any hazards or complications $^{(12,13)}$.

Hence, this study will be done to assess safety nursing measures which are applied for the patients undergoing upper GI endoscopy hoping that the findings will be a guide towards keeping patients safety throughout the whole time periods of the endoscopy procedure. The present study research question is to determine if there are safety nursing measures applied for patients undergoing upper gastrointestinal endoscopy or not.

\section{Aim of the Study}

The aim of this study is to assess safety nursing measures applied for the patients undergoing upper gastrointestinal endoscopy.

\section{Research Question:}

Are there safety nursing measures applied for patients undergoing upper gastrointestinal endoscopy? 


\section{Materials and Method}

\section{Materials}

Design: A descriptive research design was utilized in the present study.

Settings: The study was carried out at 18 gastroenterology endoscopy units, of them 12 units in Alexandria governorate and 6 units in Damanhour city in order to obtain reasonable number of nurses' subjects. These units were presented in the following settings, University Hospitals, Gamal Abd Elnaser Health Insurance Hospital, Private hospitals and Governmental hospitals.

Subjects: Consisted of all nurses (50 nurses) working in the previously mentioned settings.

Tools: Two tools were developed by the researcher and were utilized in order to fulfill the study aim:

Tool I: Upper gastrointestinal endoscopy unit assessment checklist ${ }^{(14-17)}$

It was developed by the researcher to assess upper gastrointestinal endoscopy unit's physical setup, and comprised 64 items that included:

Reception and waiting areas: It contained six items related to: being large enough to accommodate patients and companions, has proper waiting seats, has enough light either day light and or electrical light, designed so that patients being transferred to the procedure area with minimum exposure to post-endoscopy patients or the endoscope, has a private area for discussing financial or personal information and adequate patient toilet facilities close to the reception area.

Preparation area: It included ten items related to: being well ventilated, has enough light, seating for patient/companion, carts for linens, locker to store patients' clothing and personal belongings, locker to hold adequate patient care supplies and equipment which include: venipuncture needles, tourniquets, alcohol sponges, adhesive tape, clean gowns and identification bands, blood pressure apparatus, thermometers and oxygen source either central or cylinder and has adequate patient toilet facilities close to preparation area.

Procedure room: It comprised seventeen items related to: being located in the interior of the building without windows; the clear floor area should accommodate a full 360degree turning radius of the procedure table, allow easy access for the assistant to a hand washing sink, has varying light level facilities, strong ventilation system(air conditioner), a small workstation with a task light, a telephone or intercom system, locker to hold endoscopy accessories, enclosed overhead storage for linens and suction containers, mobile carts to hold the necessary equipment and supplies for the procedure, the light source and video monitors are placed vertically on mobile carts and conveniently for endoscopists and assistants, the carts have adjustable shelving and internal power strips with wiring channels, suction devices, ECG monitor, pulse oximeter, piped oxygen source, resuscitation facilities including: cardiac defibrillator and emergency drugs.

Recovery area: It comprised fifteen items related to: being well ventilated, has enough light, reclining chairs, trolley or hospital beds separated by cubicle curtains, adjacent to each recovery stretcher at least one chair for a relative / companion, a nurses' control station with a medication preparation area, hand-washing sink, patient's toilet, lockers for medical supplies, lockers for linen, suction devices, ECG monitor, pulse oximeter, piped oxygen source and resuscitation facilities including: cardiac defibrillator and emergency drugs.

Reprocessing/decontamination area: It included seven items related to: being closed area, well ventilated, has enough light, several oversized sinks to clean gross material from scopes, adequate counter space for accessory cleaning materials and equipment, an accessory washer to handle dilators, biopsy forceps separately, and 
work surfaces of 30" depth in order to accommodate an automatic endoscope washing machine.

Endoscope, equipment/supply storage area: It contained six items related to the availability of: a location where instruments can be hanged freely, the cabinet accommodates a drip pan to collect residual moisture from scopes hanging to dry after flushing it with either alcohol or air, the cabinet that has doors not causes a risk for damaging the scope tubes, cabinets incorporating ventilation and temperature control, subdivided storage area for other endoscopy accessories and lockers for surgical attire-dresses, suits, caps, and shoes covers.

Nursing manager office: It contained three items related to: being furnished with modular furniture, seating, overhead storage shelves, accessories for paper handling and Patient information display system.

N.B: Tool one structured sheet comprised 5 columns. One column for the items of adequate physical setup facilities and column 2,3 and 4 for checking the adequacy and availability of facilities either available and adequate, available and inadequate or not available and the column 5 is a blank space for writing researcher's remarks.

Tool II: Upper gastrointestinal endoscopy safety nursing measures observational checklist

This tool was developed by the researcher after review of the related literature ${ }^{(18-22)}$ to assess safety nursing measures that are applied by every nurse before, during and after upper gastrointestinal endoscopy procedure. The tool comprised 132 items related to the safety nursing measures that were observed by the researcher during the three time periods (before, during and after) the procedure in each previously mentioned settings. The items are categorized in three parts as follows:

Part I: Safety nursing measures applied before upper gastrointestinal endoscopy procedure: This part contained 32 items related to safety nursing measures before the procedure that included:

- Psychological safety included five items related to: being gentle and calm while the assigned nurse is dealing with the patient after introducing herself, gives adequate explanation of the procedure, answers all questions and informs the patient about pre procedure instructions.

- Mechanical safety which included eight items related to: checking the efficiency of all needed equipment and devices to ensure that they are intact and functioning properly including: blood pressure apparatus, thermometer, oxygen source either central or cylinder, wheel chairs. Preparing all supplies which are needed for pre-procedure patient's preparation including: cannula of different sizes, syringes, alcohol swab, identification bands and clean gown.

- Physical safety consisted of sixteen items related to: check patient's identification information, obtaining the patient history about associated diseases, allergy, current use of either prescribed or over the counter medication. Obtaining patient written informed consent, proper clinical status and risk assessment, checking the patient's medical record for completeness and presence of all requested diagnostic results, ensuring that patient is fast at least 6-8 hrs before procedure, instructing the patient to remove any dentures, hearing aids, prosthesis, jewelers , contact lenses, makeup and nail polish. Obtain patient's vital signs baseline data, inserting peripheral line in patient's arm; ensure that patients with heart valve disease receive prophylactic antibiotics.

- Bacteriological safety comprised three items related to: ensure that 
patient wear clean gown and overhead cap, perform hand washing with soap and water before and after patient care.

Part II: Safety nursing measures applied during upper gastrointestinal endoscopy procedure: This part contained 47 items related to safety nursing measures during the procedure that included:

- Electrical safety which comprised three items related to: removing defective wires and exposed plugs and fuses, keeping the electric connections not touched with wet hands and wet floor and rechecking that the circuits are not over loaded.

- Thermal safety which included two items related to: ensuring no smoking in the endoscopy unit and rechecking that the fire extinguisher is charged.

- Instrumental and mechanical safety included thirteen items related to: rechecking efficiency of all apparatuses needed for the procedure including ECG monitors, pulse oximeter, anesthesia and suction apparatus, piped oxygen source, video monitor and sterile endoscopes, adjust procedure table height and check its mechanical efficiency, keeping the floor dry at all procedure times, giving directional signals to staff assisting in moving patient and protect patient from fall through close monitoring and raise trolley side rails.

- Psychological safety contained two items related to: giving instructions during the procedure to the patient in a simple and tender manner and keeping patient's privacy.

- Bacteriological safety included five items related to: nurse preparing herself for procedure through hand washing, wear clean apron/gown, gloves, eye goggles and face masks.

- Physical safety comprised twenty two items related to: orally confirming both patient identity and type of recommended upper GI endoscopy procedure, assisting the patient to assume proper position, attaching the patient to cardiac monitor, blood pressure cuff, pulse oximetry, and oxygen source, placing mouth guard in the patient's mouth, assisting the endoscopist in spraying numbing medication into the back of patient's throat and administrating sedative medication into peripheral line, monitoring patient's cardiorespiratory status continuously throughout the procedure including: heart rate, respiratory rate, blood pressure, and oxygen saturation, appropriate assistance and handling endoscopist with needed supplies and equipment including: sterile dressing, cotton swab, sedatives, antidote for anesthesia, and crush cart. Placing biopsy in securely cupped container and label it accurately.

Part III: Safety nursing measures applied after upper gastrointestinal endoscopy procedure: This part contained 19 items related to safety nursing measures after the procedure which included:

- Physical safety which comprised sixteen items related to: assessing patient's level of consciousness, vital signs and oxygen saturation at least every 15 minutes for the 1 st hour. Monitoring patient's cardiopulmonary status until the sedative medication has worn off, applying oral suction and administering oxygen as needed, test gag and cough reflexes, accurate documentation of the following: type and time of upper GI procedure, vital signs, $\mathrm{O}_{2}$ saturation, drugs which had been given, any reaction happened and its management, name of anesthesiologist, endoscopist and his assistant in both patient's chart and unit's record. Informing 
patient with all post procedural instructions that included: nothing per mouth until local anesthesia has worn off and gag reflex has returned, not to drive car, operate machinery, or drink alcohol until 24 hours have elapsed after the endoscopy, need for responsible adult to accompany patient to home, notifying the doctor if he develops any of the following: fever/chills, abdominal pain, nausea, vomiting, bloody stool, swallowing difficulties and throat or chest pain that worsens.

- Psychological safety which included three items related to: maintaining calm and quite environment surrounding the patient, continuous reassurance while keeping patient's privacy during the process of recovery.

- Reprocessing of endoscopes and accessories equipment. Which contained 34 items related to the following:

1. Preliminary cleaning: It included three items related to: wearing a heavy domestic grade rubber gloves, apron, mask and eye protective/shield, flushing endoscope channels immediately (air/water flushing valve) following the procedure and cleaning its external surfaces, transport the endoscopes to the decontamination area in a covered receptacle that is of an appropriate size.

2. Manual cleaning: It comprised eleven items related to: removing the endoscope valves and its detachable distal tips from the endoscope prior to manual cleaning, testing for leak and inspecting endoscopes for damage prior to manual cleaning, ensuring that correct manual cleaning is carried out in a dedicated sink and is filled with water to an identified level to detergent concentration and temperature in accordance to manufacturer's instructions, flushing the detergent solution through the device lumen using sterile syringe, brushing all accessible channels and ports using a correct size cleaning device for that channel, checking visually valves to ensure that are clean and not damaged, ensuring the cleaning device (brush) is visibly clean at the end of the process, cleaning the external surfaces of the endoscope, discarding detergent and water solutions after each use, transferring endoscopes to a sink separate to that used for manual cleaning for rinsing with clean water, keeping removable parts with the endoscope to form a unique set of equipment.

3. Disinfection: It included five items related to: mixing the disinfectant according to manufactories instructions and label it with the expiration date, immersing all internal and external surfaces of the parts in contact with the disinfectant, ensuring that all internal and external surfaces and channels are in contact with the disinfecting agent for at least 20 minutes, rinse the endoscope with sterile water, transferring endoscopes to the Automated Endoscope Reprocessing machines (AER) in an appropriately sized receptacle.

\section{Automated Endoscope} Reprocessing machines (AER): It contained seven items related to: reprocessing all endoscopies using an AER following manual cleaning with the appropriate connections to ensure irrigation of all channels, ensuring that all channels are connected to the AER prior to starting the cycle, ensuring that all AERs and associated water 
treatment systems should undergo a self-disinfect cycle at the beginning of each day, inspecting connectors prior to removal of the endoscope on completion of the cycle to confirm all channels have been irrigated, verifying that the cycle was successful and complete which is obtained from the print out or via electronic means prior to removal from the AER, rinsing the decontamination cycle finally with bacteria free water, drying external surfaces of the endoscope well using sterile towels or special air dryer.

5. Storage of endoscopes: included three items related to: storing endoscopes in a suitable cabinet where residual fluid does not remain in the channels, storing endoscopes with their detachable parts in a manner that ensures security of the items and keeps its components together as a unique set, reprocessing endoscopes if more than 3 hours has elapsed from the last decontamination process.

6. Care of accessories: comprised five items related to: ensuring that single use biopsy forceps should be used for all procedures, ensuring that all accessories should be single use unless no suitable alternative is obtainable, ensuring that reusable accessories that can be autoclaved are inspected, manually cleaned, packed appropriately and sent to the sterile supply department (SSD) for sterilization, cleaning endoscopy water bottles manually and sending it to the sterile supply department (SSD) for sterilization, changing water bottles with sterile water after each endoscopy session.

N.B: Nurses Socio-demographic Data Structured Interview Schedule was attached to tool II and it included items related to: nurse qualification, endoscopy working setting, years of experience in endoscopy unit, previous attendance of pre and inservices training related to gastroenterology endoscopy procedures.

\section{Scoring system:}

Tool I: Each gastrointestinal endoscopy unit's physical setup structure and facilities was assessed for its availability and adequacy, and scored as follows:

Available and adequate $=2$ (safe facility), Available and inadequate $=1$ (unsafe facility) and Not available $=0$.

- The score range of safety provided by each physical setup structure area was calculated using the above mentioned scoring system. The score ranges were: for reception and waiting area (0-12), preparation area (0-20), procedure room (0-34), recovery area (0-30), reprocessing/decontamination area $(0$ 14), endoscope, equipment/supply storage area (0-12) and nursing manager office (0-6). The adequacy of the facility was judged according to its sufficiency for patient's privacy, physical and psychological comfort and safety.

Tool II: Each item in this tool was checked and scored on a three point rating scale as follows:

Done correctly=2 (safe nursing measures), Done incorrectly $=1$ (unsafe nursing measures) and Not done $=0$.

- The score range of each part of safety nursing measures was calculated using the above mentioned scoring system. The score ranges were: for part I (064) this number then was multiplied by three (No of observations per nurse), part II (0-94) this number then was multiplied by three (No of observations per nurse) and part III (0- 106) this number then was multiplied by three (No of observations per nurse). The items which were performed correctly without mistakes are considered the safe practice. 


\section{Method}

- A written approval to carry out the study was obtained from the hospital responsible authorities at the previous mentioned settings after explanation of the study purpose.

- The tools were constructed by the researcher after review of relevant literature and were tested for content validity by five faculty members from medical surgical department, faculty of nursing Alexandria University.

- Study tools were tested for its reliability using Alpha Cronbach's statistical test for internal consistency of tool items. Alpha Cronbach's reliability of tool one was (0.735) and tool two (0.762).

- A pilot study to test feasibility, clarity and applicability of tools were carried out on five of the endoscopy nurses through assessing their practice of safety nursing measures before, during and after performing upper gastrointestinal endoscopy procedure at the previously mentioned settings before starting the data collection.

- Tool one assessment was done before the observations of the nurses' performance. Every nurse was observed before, during and after upper gastrointestinal endoscopy procedure Using tool two. Nurses' were not aware that they were observed for their performance in order to achieve objectivity in data collection.

- Data were collected over duration of 6 months from the middle of Nov 2012 till the middle of May 2013.

\section{Ethical considerations:}

Nurse's oral consent was obtained for approval of the researcher attendance before, during and after the endoscopy procedure. Nurses were informed that their confidentiality and anonymity will be assured.

\section{Statistical Analysis}

The collected data were revised, coded and fed to statistical software SPSS version 16. The findings were tabulated with presentation of the appropriate statistical tests, the given graphs were constructed using Microsoft excel software. Statistical analysis was done using two tailed tests and alpha error of 0.05 . $\mathrm{P}$ values less than or equal to 0.05 were considered significant.

\section{Results}

\section{Part I: Demographic characteristics of the studied nurses:}

Table (1) presents distribution of the studied nurses according to their demographic characteristics $(\mathrm{N}=50)$. The table reveals that the number of nurses, who worked at both university hospitals and the private hospitals and clinics were 19 nurses with a percentage of 38.0 each. The percentage of the nurses worked at the governmental hospitals was $14.0 \%$ and the remaining number (5 nurses) worked at the health insurance hospital with a value of $10.0 \%$. Moreover $74.0 \%$ of the studied nurses were holding diploma of the nursing secondary school, $18.0 \%$ had Bachelor degree, while $8.0 \%$ of the nurses graduated from technical institute of nursing. In addition the table shows that the years of experience of the studied nurses ranged from <5-10+ years distributed as: $48.0 \%$ had experience less than 5 years, $26.0 \%$ had experience from 5 to less than 10 years and $26.0 \%$ of the nurses had more than 10 years of experience. The median of the nurses' experience was 5.0 years with a range of 0.5 to 20 years. The table also reveals that $38.0 \%$ of the nurses attended in-service training related to GI endoscopy procedure, while $62.0 \%$ did not receive any. 
Part II: Description of upper GI endoscopy unit's physical setup structure at the different study settings:

Figure (1) represents ranking of mean scores of upper GI endoscopy unit's physical setup facilities at the different study settings. The figure illustrates that the highest mean scores of facilities in reception and waiting area with value of 8.4 was at the private hospitals and clinics, compared 5, 4.7 and 4 at governmental hospitals, university hospitals and health insurance hospital respectively. The figure likewise shows that the highest mean scores of facilities in preparation area with a value of 9.9 was at the private hospitals and clinics, compared to $8.5,8$, and 7 at governmental hospitals, health insurance hospital, and university hospitals respectively. Moreover, the figure also reveals that the highest mean scores of facilities in procedure room with a value of 30 was at the private hospitals and clinics, compared to 29,27 , and 25 at health insurance hospital, university hospitals and governmental hospitals respectively.

The figure also illustrates that, the highest mean scores of facilities in recovery area was 15.6 at the private hospitals and clinics, compared to $10.5,10.2$, and 5 at governmental hospitals, university hospitals, and health insurance hospital respectively. As well the highest mean scores of facilities in the reprocessing area with a value of 11 was at the health insurance hospital, compared 7.2, 6, and 5.2 at private hospitals and clinics, governmental hospitals, and university hospitals respectively.

It can be noticed that; the highest mean scores of facilities in endoscope/equipment and supply storage area with a value of 7.6 was at the private hospitals and clinics, compared to $6,5.8$, and 4 at health insurance hospital, university hospitals, and governmental hospitals respectively. Highest mean scores of facilities in nursing manager office were 4 at the health insurance hospital, compared to 3, 2.1, and
2 at university hospitals, private hospitals and clinics, and governmental hospitals respectively.

Part III: Safety nursing measures applied by the nurses for upper GI endoscopy procedure:

Table (2) shows minimum, maximum, mean scores, standard deviations and median of safety nursing measures before, during and after upper GI endoscopy procedure. Concerning safety nursing measures before upper GI endoscopy procedure, the table reveals that; the highest mean percent practice score was $53.3 \%$ $(28.8 \pm 8.4)$ for mechanical safety, while median score was 31.5 , compared to the lowest mean percent practice score which was $25.5 \%(4.6 \pm 3.4)$ for bacteriological safety while, median score was 4.0.

Regarding safety nursing measures during upper GI endoscopy procedure, the table shows that; the highest mean percent practice score was $70.0 \%(8.4 \pm 2.7)$ for psychological safety, while median score was 9.0, compared to the lowest mean percent practice score which was $35.6 \%$ $(10.7 \pm 2.8)$ for bacteriological safety, while median score was 10.5

In relation to, safety nursing measures after upper GI endoscopy procedure; the highest mean percent practice score was $62.7 \%(11.3 \pm 4.2)$ for psychological safety, whereas median score was 12.0, compared to the lowest mean percent practice score $15.2 \%(6.4 \pm 11.5)$ for reprocessing of endoscopes using Automated Endoscope Reprocessing machine (AER).

Part IV: Correlation between safety nursing measures scores of upper GI endoscopy procedure and nurses' demographic characteristics:

Table (3) presents correlation between safety nursing measures scores before upper GI endoscopy procedure and nurses' demographic characteristics. The table reveals that; the highest mean percent practice score regarding safety nursing measures before upper GI endoscopy 
procedure was $40.3 \%$ for the nursing staff at the private hospitals and clinics, while median score was 80.0 which mean that most of the nurses at private hospitals and clinics provide safety measures before procedure correctly. This is compared to the lowest mean percent practice score which was $31.3 \%$ for the nursing staff at health insurance hospital, while median score was 60.0. The table also reveals that the practices differences between the four study settings were not statistically significant where $\mathrm{p}=0.272$.

Regarding level of education, this table shows that the nurses with bachelor degree had a significantly higher mean percent practice score than the nurses with technical institute of nursing and those with diploma of secondary nursing school (mean\% scores $=50.0 \%, \quad 41.6 \%$ and $35.6 \%$ respectively) $\mathrm{p}=0.001 *$ while, median score were 94.0, 76.5 and 69.0 respectively.

Concerning years of experiences, the table reveals that the nurses with more than 5 to less than 10 years of experience had a significantly higher mean percent practice score than the nurses with less than 5 and those with more than 10 years of experience (mean \% score $=43.0 \%, 40.0 \%$ and $32.0 \%$ respectively) $\mathrm{p}=0.026 *$ while, median score were 85.0, 79.5 and 48.0 respectively.

Regarding pre and in-service training related to the GI endoscopy procedure, the nurses who received training, had a significantly higher mean percent practice score than the nurses who had no training $($ mean $\%$ scores $=44.5 \%$ and $35.1 \%$ respectively) $\mathrm{p}=0.003 *$ while, median scores were 85.0 and 71.0 respectively.

Table (4) illustrates correlation between safety nursing measures scores during upper GI endoscopy procedure and nurses' demographic characteristics. The table reveals that the highest mean percent practice score regarding safety nursing measures during upper GI endoscopy procedure was $62.9 \%$ for the nursing staff at the private hospitals and clinics, while median score was 166.0 which mean that most of the nurses at the private hospitals and clinics provide safety measures during procedure correctly. This is compared to the lowest mean percent practice score which was $50.4 \%$ for the nursing staff at the governmental hospitals, while median score was 158.0. The table also shows that the practices differences between the four study settings were statistically significant where $\mathrm{p}=0.011^{*}$.

Regarding level of education, the table reveals that the nurses with technical institute of nursing had a significantly higher mean percent practice score than the nurses with bachelor degree and those with diploma of secondary nursing school (mean\% score $=65.5 \%, 63.8 \%$ and $52.3 \%$ respectively) $\mathrm{p}=0.012 *$ while, median score were $185.5,193.0$ and 156.0 respectively.

Concerning years of experiences, the table shows that nurses with less than 5 years of experiences had a significantly higher mean percent practice score than nurses with more than 5 to less than 10 years of experience and more than 10 years of experience (mean \% scores $=59.5 \%$, $56.9 \%$ and $46.4 \%$ respectively) $\mathrm{p}=0.008^{*}$ while, median score were $163.0,156.0$ and 121.0 respectively.

Regarding pre and in-service training related to the GI endoscopy procedure, the nurses who received training, had a significantly higher mean percent practice score than the nurses who had no training (mean $\%$ scores $=55.9 \%$ and $51.0 \%$ respectively) $\mathrm{p}=0.001 *$ while, median scores were 160.0 and 150.0 respectively.

Table (5) presents correlation between safety nursing measures scores after upper GI endoscopy procedure and nurses' demographic characteristics. The table illustrates that the highest mean percent practice score regarding safety nursing measures after upper GI endoscopy procedure was $35.3 \%$ for the nursing staff at the private hospitals and clinics, while median score was 39.0. This is compared to 
the lowest mean percent practice score which was $26.2 \%$ for the nursing staff at the governmental hospitals, while median score was 30.0. The table also reveals that the practices differences between the four study settings were statistically significant where $\mathrm{p}=0.003^{*}$ Regarding level of education, the nurses with bachelor degree had a significantly higher mean percent practice score than nurses with technical institute of nursing and those with diploma of secondary nursing school (mean \% scores $=39.2 \%, \quad 32.7 \%$ and $32.0 \%$ respectively) $\mathrm{p}=0.009^{*}$ while, median scores were 47.0, 36.0 and 36.0 respectively.

Concerning years of experiences, this table shows that the nurses with more than 5 to less than 10 years of experience had higher mean percent practice score than the nurses with less than 5 years of experiences and those with more than 10 years of experience (mean \% scores $=35.5 \%, 33.1 \%$ and $31.7 \%$ respectively) while, median scores were 38.0, 37.5 and 33.0 respectively. These differences between the nurses' years of experience were not statistically significant where $\mathrm{p}=0.336$

Regarding pre and in-service training related to the GI endoscopy procedure, the nurses who received training, had a significantly higher mean percent practice score than the nurses who had no training (mean \% scores $=35.9 \%$ and $31.8 \%$ respectively) $\mathrm{p}=0.031^{*}$ while, median scores were 40.0 and 35.0 respectively.

\section{Discussion}

The growth of GI endoscopy as a specialized activity within health care has increased the need for specialization in both facility design and management skills. Upper GI endoscopy procedures are carried out in a specifically designed and dedicated endoscopy suite, where full monitoring throughout each procedure is done. Patients are assessed before, during and after each endoscopic procedure, by specialized and certified nurses $^{(3,4)}$.
Patient safety is the high-quality health care team activity, which was defined by the Institute of Medicine (IOM) as "the prevention of harm to patients; freedom from accidental or preventable injuries produced by medical care." Patient safety practices have been defined as "Those practices that reduce the risk of adverse events related to exposure to medical care across a range of diagnoses or conditions, ${ }^{(23)}$.

The present study was conducted on four upper GI endoscopy settings; the university hospitals, private hospitals and clinics, health insurance hospital, and governmental hospitals. On assessing the endoscopy units' physical setup structures and facilities in relation to reception and waiting areas, the difference of mean scores of the total items among the four study settings in relation to the availability and adequacy of structure and facilities were not statistically significant. This denotes that all the settings regarding reception and waiting areas need more promotion in order to fulfill its functions for registration, waiting, and allowing opportunities for patient education.

In relation to preparation area the study results showed that the difference of mean scores of the total items among the four study settings in relation to the availability and adequacy of structure and facilities in the preparation area were not statistically significant. This indicates that all the settings regarding preparation area need more promotion in order to achieve the pre procedure patient's psychological, physical and bacteriological safety.

In relation to procedure room, the findings revealed that; the difference of mean scores of the total items among the four study settings in relation to the availability and adequacy of structure and facilities in the procedure room were not statistically significant. This illustrates that all study settings need more promotion for both procedure room physical setup structure design and its required facilities in 
order to achieve patient's physical safety during the procedure. This explanation agreed with Kandil (2004) who reported that the unavailability of standard physical setup of endoscopy procedure room may -in part- be due to lack of a basic endoscopy unit design within the structure from the beginning $^{(24)}$.

In relation to recovery area the study results revealed that; the difference of mean scores of the total items among the four study settings in relation to the availability and adequacy of structure and facilities in the recovery area were not statistically significant.

In relation to reprocessing/ decontamination area, the study results showed that the lowest mean score of the total items regarding decontamination area was for university hospitals. This is due to the fact that the endoscopy units design at the Alexandria Main University Hospital had no decontamination area and the reprocessing of the endoscopes was done in the procedure room. In this regard Gaiso (2003) emphasized that reprocessing of contaminated patient's equipment should be done in an area designated and dedicated for this function. This should be carried out in an area separated from the room where endoscopic procedures are performed.This prevent cross infection and contamination in endoscopy procedures room ${ }^{(25)}$.

In relation to endoscope, equipment and supply storage area, the clean and dry endoscope storage space is required, and should be physically separated from decontamination and cleaning areas ${ }^{(26)}$. The study findings revealed that the difference of mean scores of the total items related the availability and adequacy of structure and facilities in the endoscope, equipment and supply storage area of the private hospitals and clinics was significantly higher than the other three study settings. These three settings were lacking in the facilities related to; the cabinet with a drip pan, the cabinet door that do not cause risk for damaging the endoscope tubes, and the cabinet incorporating ventilation and temperature control.

In the same line Bradley and Catalone (2010) mentioned that a proper storage environment is one that both protects the endoscope from damage and minimizes environmental contamination. The multisociety guidelines call for storing endoscopes in a manner that will protect it from contamination. During storage, endoscopes should be stored uncoiled, hanging vertically in a clean, dry, ventilated area to facilitate drying, with caps, valves and other detachable components removed following the manufacturer's instructions, and stored separately from endoscopes to avoid accidental punctures or cuts ${ }^{(27)}$. In addition Muscarella (2013) stated that the endoscope reprocessing guidelines recommending that the reprocessed and dried endoscope be vertically hung in storage cabinet ${ }^{(28)}$.

Regarding nursing manager office the study findings revealed that; the difference of mean scores among the four study settings in relation to the availability and adequacy of structure and facilities in the nursing manager office were not statistically significant. This refers that all the settings regarding nursing manager office need more promotion in order to maintain relevant, accurate and complete recording of each endoscopy procedure for every patient.

In relation to safety nursing measures applied by the nurses before, during and after upper GI endoscopy procedure, the highest level of nurses' practice of safety measures before upper GI endoscopy procedure was related to mechanical safety followed by psychological, physical and bacteriological safety respectively. The highest level of nurses' practice of safety measures during upper GI endoscopy procedure was related to psychological safety followed by physical, mechanical, thermal, electrical, and bacteriological safety respectively. 
Also it was observed that, the highest level of nurses' practice of safety measures after upper GI endoscopy procedure was related to psychological safety followed by physical safety respectively, and the highest level of nurses' practice of safety measures regarding decontamination/reprocessing of endoscopes was related to storage followed by manual cleaning, disinfection, preliminary cleaning care of accessories and AER machine respectively. This result was in line with Mahajan and Wyllie (2002) who found that psychological preparation significantly decreased patient and parental anxiety. Such preparation may allow for reduction in sedative medications and thereby enhance procedural safety ${ }^{(29)}$.

The correlation between safety nursing measures scores before upper GI endoscopy procedure and nurses' demographic characteristics revealed that, the highest mean percent practice score was for private hospitals and clinics nursing staff, which means that most of the nurses in private hospitals and clinics provided safety measures before procedure correctly. This outcome may be related to availability of most of facilities, equipment and supplies within adequate physical setup structure of endoscopy units at those private settings. This was followed by university hospitals and governmental hospitals nursing staff, while the lowest mean percent score was for nursing staff of the health insurance hospital. However, the practice differences before the procedure were not statistically significant among the four study settings.

The findings also showed that nurses with bachelor degree had a significantly higher mean percent practice score than technical nurses graduated from technical heath institutes of nursing and other nurses with diploma of secondary nursing schools. This means that education has a significant effect on nurses' knowledge and performance of safety nursing measures before the procedure. It could be attributed to sufficient information given in undergraduate courses related to GI endoscopy and nursing role in the procedure in the baccalaureate nursing program. In this context Kopfer and McGovern (2003) reported that education was a potential means for implementing preventive strategies as it may attribute in altering perception, increasing knowledge and in turn changing work practice ${ }^{(30)}$.

The study results also revealed that nurses with more than 5 to less than 10 years of experience had a significantly higher mean percent practice score than nurses with less than 5 and those with more than 10 years of experience. This may be related to the fact that nurses with more than 5 to less than 10 years of experience were considered as senior at endoscopy unit, because they had adequate experience and performance and they probably received training program related to the GI endoscopy procedure. Many nurses with long years of experience were not involved in direct patient care and managed the administrative work. This finding was incongruent with Mokhter (2008) who mentioned that "nurses' experience had no significantly effect on both nurses' knowledge and performance". (31).

The results also revealed that nurses who received pre and in-service training related to the GI endoscopy procedure had a significantly higher mean percent practice score than nurses who had no training. This result was supported by Hadded (2002) who reported that in-service educational and training program had significant effect in improving the nurses' knowledge and skills regarding nursing care to patient with medical surgical disorders ${ }^{(32)}$.

The correlation between safety nursing measures scores during upper GI endoscopy procedure and nurses' demographic characteristics showed that the nurses in the private hospitals and clinics provided more safety measures during the procedure than the other three study settings and the differences were statistically significant. This may be related to availability of most of facilities, 
equipment and supplies within adequate physical setup structure and facilities of endoscopy units at those private settings, in addition to adequate nursing supervision on nurse's performance at those units.

The results also revealed that technical nurses graduated from technical heath institutes of nursing had a significantly higher mean percent practice score than nurses with bachelor degree and other nurses with diploma of secondary nursing schools. This may be justified that many of technical nurses considering their main responsibilities is technical work in most endoscopy units especially during care provided during the procedure. While highly educated nurses are responsible for supervision and nurses who had nursing diploma responsible for porter work.

The findings also showed that nurses with less than 5 years of experiences had a significantly higher mean percent practice score than nurses with more than 5 to less than 10 years of experience and those with more than 10 years of experience. The possible explanation may be that the nurses with long years of experience belief that the clinical practices during procedure are the core work of nurses with short years of experience.

The results also revealed that nurses who received pre and in-service training related to the GI endoscopy procedure, had a significantly higher mean percent practice score than nurses who had no training. In this respect, in-service training and educational programs always keep nurses familiar with the recent advances in their area of specialty, maintain their speed and efficiency in carrying out their respective activities and so the quality of care will be improved $^{(33)}$.

The correlation between safety nursing measures scores after upper GI endoscopy procedure and nurses' demographic characteristics revealed that the highest mean percent practice score was significant for private hospitals and clinics nursing staff. This was followed by university hospitals nursing staff and health insurance hospital nursing staff. The lowest mean percent practice score was for nursing staff at governmental hospitals. It was observed that the physical setup structure and facilities of endoscopy units at those hospital settings were not adequate, since no decontamination areas were available and the decontamination of endoscope and its accessories were done in the same procedure room. In addition those hospitals were lacking of supervision of nurse's performance.

It was also observed that nurses with bachelor degree had significantly higher mean percent practice score than technical nurses graduated from technical health institutes of nursing and those with diploma of secondary nursing schools. This denotes that education has a significant effect on nurses' knowledge and performance of safety nursing measures after the procedure. In this respect, Guilbert, (2000) mentioned that the effective professional education requires close and more proportion connection between theory and practice. Furthermore, nurses' educational level has a great impact on their knowledge while caring of patients ${ }^{(34)}$.

The findings also showed that nurses with more than 5 to less than 10 years of experience had high mean percent practice score than nurses with less than 5 years of experiences and those with more than 10 years of experience. This is may be due to the fact that many of the nurses with 5 to less than 10 years of experience had received in-service training related decontamination of endoscopy and its accessories; thereby they are experts enough to provide post procedure care. Moreover, it was observed that they take responsibility of training for other nurses with shorter experience which could make them act as role model for those nurses, while nurses with longer experience take responsibilities of administrative work after the procedure. 
Also nurses who received pre and inservice training related to the GI endoscopy procedure had a significantly higher mean percent practice score than nurses who had no training. In the same line Streubert and Carpenter (2003) stated that in-service education is one way in which nurses maintain currency in their field and the focus of in-service educational program is specifically job related $^{(35)}$.

Finally, it can be observed that nurses' performance regarding safety nursing measures for patient undergoing upper GI endoscopy procedure are significantly influenced by physical setup structure and endoscopy unit facilities at the different study settings. In addition to the practices of safety nursing measures before, during and after the procedure are influenced by nurses' demographic characteristics including: level of education, years of experience and receiving training programs related to the GI endoscopy procedure. Consequently, the weakness of the mostly performed safety nursing measures for upper GI endoscopy procedure would expose the patients' to physical, psychological, mechanical, thermal, electrical and bacteriological hazards.

\section{Conclusion}

- The upper gastrointestinal endoscopy unit's physical setup structure and facilities of the four study settings were below the standard. The highest available and adequate structure and facilities were found in the private hospitals and clinics followed by health insurance, university and governmental hospitals respectively.

- The highest level of nurses' practice of safety measures before upper GI endoscopy procedure was related to mechanical safety while during and after the procedure was related to psychological safety.

- Nurses' practice was influenced by their demographic characteristics. As those who were working in the private hospitals and clinics illustrated higher safety measures than those who were working in the other three study settings. There was no difference of nurses' practice before the procedure and in decontamination/ reprocessing of the endoscopes among the four study settings.

- Practice of nurses' with bachelor degree illustrated higher safety measures than those with technical and secondary schools diploma before and after the upper GI endoscopy procedure. While the nurses' with technical institute of nursing illustrated higher safety measures during the procedure than the other nurses.

- Practice of nurses' with more than 5 to less than 10 years of experience illustrated higher safety measures than those with less than 5 years of experience and those with more than 10 years of experience before and after the upper GI endoscopy procedure. The nurses' with less than 5 years of experience illustrated higher safety measures during the procedure than other nurses.

- Practice of nurses' who received pre and in-service training related to the GI endoscopy procedure, illustrated more safety measures than those who didn't receive such training programs.

\section{Recommendations}

Based on the findings of the current study the following recommendations are suggested:

- Hospital administrators and endoscopy units managers should collaborate in order to raise the upper GI endoscopy procedural safety through: 
- Revision of the units' physical structure design and facilities in order to reach the optimal standard evidenced in the present study.

- Provision of pre-service and inservice training programs for nurses working in upper GI endoscopy units.

- Emphasizing the concept of patients safety in constructing the training programs and that the integration between practice and all safety domains should always be considered.

- Utilization of the strengths and weakness that revealed in the present study findings as evidence base in constructing the training programs.

- Facilitating regular annual selfappraisal for the application of safety measures for patients undergoing upper GI endoscopy procedure.
- Educational units in undergraduate nursing programs related to the endoscopy procedures should incorporate the findings of the present study as evidence base.

- Recommendations for further researches:

- Developing standard of safe GI endoscopy nursing practice.

- Developing a manual of safety measures for the GI endoscopy nursing practice both in Arabic and English languages.

- Determine the barriers that are hindering the nurses' application of safety measures at the GI endoscopy unit. 


\section{$\underline{\text { Part I: }}$}

Table (1): Distribution of the Studied Nurses According to their Demographic Characteristics

\begin{tabular}{|c|c|c|}
\hline Demographic Characteristics & $\begin{array}{c}\text { No } \\
(\mathrm{N}=\mathbf{5 0})\end{array}$ & $\%$ \\
\hline \multicolumn{3}{|l|}{ Settings } \\
\hline \multicolumn{3}{|l|}{ Endoscopy units of: } \\
\hline - University Hospitals & 19 & 38.0 \\
\hline - Health insurance Hospital & 5 & 10.0 \\
\hline - Private Hospitals and clinics & 19 & 38.0 \\
\hline - Governmental Hospitals & 7 & 14.0 \\
\hline \multicolumn{3}{|l|}{ level of education } \\
\hline - Nursing Diploma & 37 & 74.0 \\
\hline - Technical institute of nursing & 4 & 8.0 \\
\hline - Bachelor & 9 & 18.0 \\
\hline \multicolumn{3}{|l|}{ Experience in years } \\
\hline - $<5$ & 24 & 48.0 \\
\hline - $5-$ & 13 & 26.0 \\
\hline - $10+$ & 13 & 26.0 \\
\hline Median (Range) & \multicolumn{2}{|c|}{$5.0(0.5-20)$} \\
\hline \multicolumn{3}{|l|}{$\begin{array}{l}\text { Pre and in-service training related to the GI } \\
\text { endoscopy procedure }\end{array}$} \\
\hline - No & 31 & 62.0 \\
\hline - Yes & 19 & 38.0 \\
\hline
\end{tabular}




\section{Part II:}
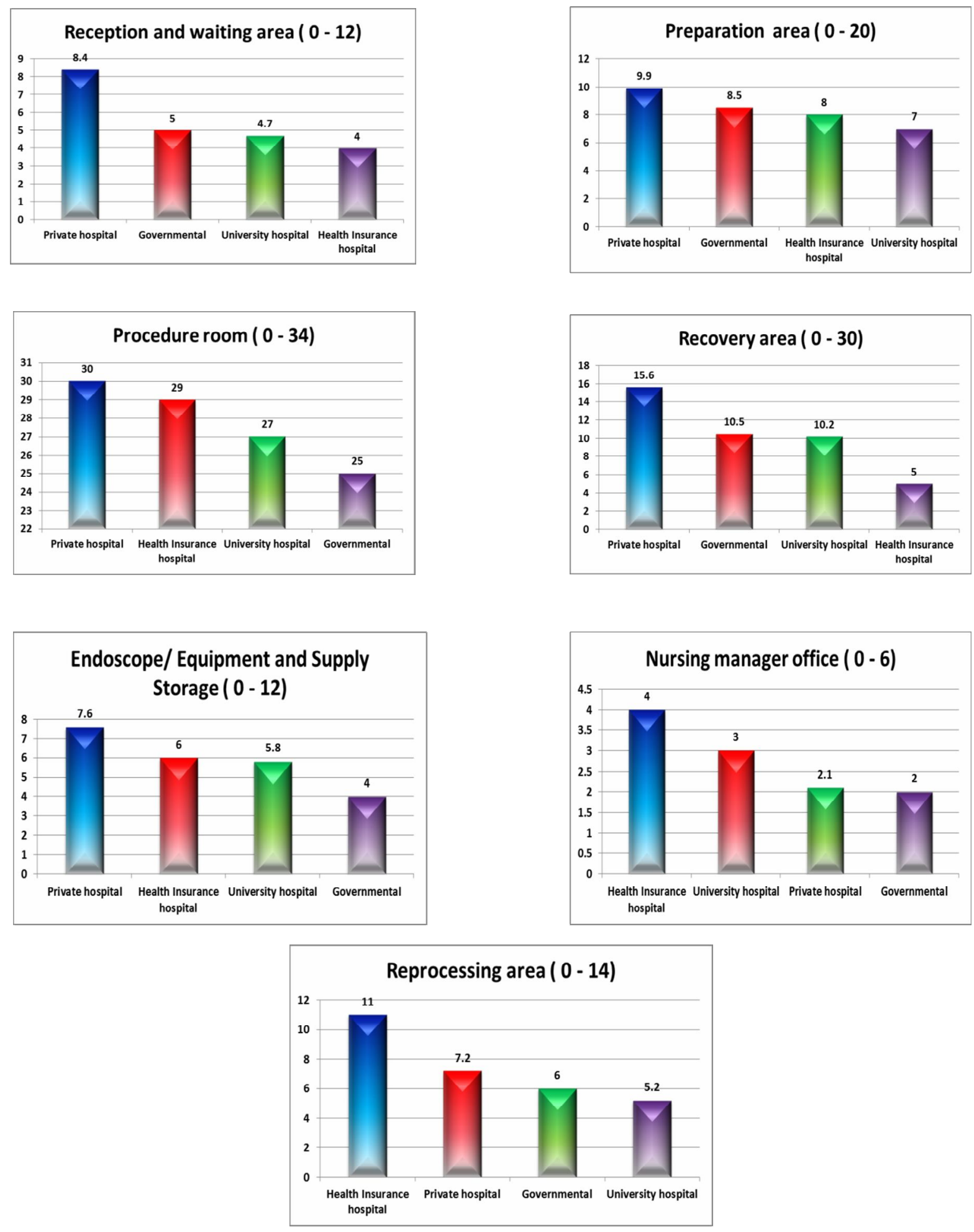

Figure (1): Ranking of Mean Scores of Upper GI Endoscopy Unit's Physical Setup Facilities at the Different Study Settings 


\section{Part III:}

Table (2): Minimum, Maximum, Mean Scores, Standard Deviations and Median of Safety Nursing Measures Before, During and After Upper GI Endoscopy Procedure

\begin{tabular}{|c|c|c|c|c|c|c|}
\hline $\begin{array}{l}\text { Safety nursing measures before, } \\
\text { during and after the upper GI } \\
\text { endoscopy procedure. }\end{array}$ & Minimum & Maximum & Mean & Mean\% & SD & Median \\
\hline \multicolumn{7}{|l|}{ 1. Before endoscopy (score range) } \\
\hline - Psychological safety (0 - 30) & 2.0 & 21.0 & 11.7 & $39.0 \%$ & 4.7 & 11.0 \\
\hline - Mechanical safety $(0-48)$ & 7.0 & 44.0 & 28.8 & $53.3 \%$ & 8.4 & 31.5 \\
\hline - Physical safety & 13.0 & 48.0 & 29.1 & $32.3 \%$ & 10.4 & 30.0 \\
\hline - Bacteriological safety $(0-18)$ & 0.0 & 14.0 & 4.6 & $25.5 \%$ & 3.4 & 4.0 \\
\hline Total $\quad(0-192)$ & 29.0 & 114.0 & 74.3 & $37.5 \%$ & 21.4 & 79.5 \\
\hline \multicolumn{7}{|l|}{ 2. During endoscopy (score range) } \\
\hline - Psychological safety (0 - 12$)$ & 2.0 & 12.0 & 8.4 & $70.0 \%$ & 2.7 & 9.0 \\
\hline - Mechanical safety $(0-78)$ & 10.0 & 64.0 & 45.3 & $58.0 \%$ & 13.3 & 46.0 \\
\hline - Physical safety $\quad(0-132)$ & 38.0 & 109.0 & 78.8 & $59.6 \%$ & 19.6 & 76.0 \\
\hline - Bacteriological safety (0-30) & 6.0 & 16.0 & 10.7 & $35.6 \%$ & 2.8 & 10.5 \\
\hline - Thermal safety $\quad(0-12)$ & 6.0 & 10.0 & 6.2 & $51.6 \%$ & 0.7 & 6.0 \\
\hline - Electrical safety & 1.0 & 12.0 & 7.1 & $39.4 \%$ & 2.1 & 6.0 \\
\hline$(0-282)$ & $\mathbf{7 0 . 0}$ & 214.0 & 156.5 & $52.3 \%$ & 36.2 & 160.0 \\
\hline \multicolumn{7}{|l|}{ 3. After endoscopy (score range) } \\
\hline - Psychological safety (0 - 18) & 2.0 & 18.0 & 11.3 & $62.7 \%$ & 4.2 & 12.0 \\
\hline $\begin{array}{l}\text { - Physical safety (0 - 96) } \\
\text { - Reprocessing of endoscopes } \\
\text { include }\end{array}$ & 20.0 & 39.0 & 26.8 & $27.9 \%$ & 5.1 & 27.0 \\
\hline$\circ$ Preliminary cleaning $(0-18)$ & 6.0 & 15.0 & 9.5 & $52.7 \%$ & 2.2 & 9.0 \\
\hline$\circ$ Manual cleaning $\quad(0-66)$ & 3.0 & 66.0 & 40.4 & $61.2 \%$ & 22.4 & 51.5 \\
\hline ○ Disinfection & 9.0 & 22.0 & 16.6 & $55.3 \%$ & 4.6 & 19.0 \\
\hline ○ AER & 0.0 & 33.0 & 6.4 & $15.2 \%$ & 11.5 & 0.0 \\
\hline ○ Storage & 12.0 & 18.0 & 13.5 & $75.0 \%$ & 2.5 & 12.0 \\
\hline$\circ$ Care of accessories $(0-30)$ & 3.0 & 16.0 & 9.6 & $32.0 \%$ & 3.0 & 9.0 \\
\hline Total $\quad(0-318)$ & 22.3 & 67.6 & 134.1 & $42.2 \%$ & 10.3 & 40.0 \\
\hline $\begin{array}{l}\text { Overall score of safety nursing } \\
\text { measures before, during and after } \\
\text { the upper GI endoscopy } \\
\text { procedure }\end{array}$ & 189.0 & 531.0 & 364.9 & $47.0 \%$ & 85.1 & 375.0 \\
\hline
\end{tabular}




\section{Part IV:}

Table (3): Correlation between Safety Nursing Measures Scores before Upper GI Endoscopy Procedure and Nurses' Demographic Characteristics

\begin{tabular}{|c|c|c|c|c|c|c|}
\hline \multirow[t]{2}{*}{ Demographic characteristics } & \multicolumn{4}{|c|}{$\begin{array}{l}\text { Safety nursing measures before upper GI } \\
\text { endoscopy procedure for the total items } \\
\qquad \text { score }=(192)\end{array}$} & \multirow[t]{2}{*}{$\mathbf{F}$} & \multirow[t]{2}{*}{$\mathbf{P}$} \\
\hline & Mean & SD & Mean\% & Median & & \\
\hline $\begin{array}{l}\text { Settings } \\
\text { Endoscopy units of: } \\
\text { - University Hospitals } \\
\text { - Health insurance Hospital } \\
\text { - Private Hospitals and } \\
\text { clinics } \\
\text { - Governmental Hospitals }\end{array}$ & $\begin{array}{l}76.3 \\
60.1 \\
77.5\end{array}$ & $\begin{array}{l} \pm 21.4 \\
\pm 5.7 \\
\pm 17.0 \\
\pm 30.9\end{array}$ & $\begin{array}{l}39.7 \% \\
31.3 \% \\
40.3 \%\end{array}$ & $\begin{array}{l}83.5 \\
60.0 \\
80.0 \\
69.0\end{array}$ & 1.3 & 0.272 \\
\hline $\begin{array}{l}\text { level of education } \\
\text { - Nursing Diploma } \\
\text { - Technical institute of } \\
\text { nursing } \\
\text { - Bachelor }\end{array}$ & $\begin{array}{l}68.4 \\
80.0\end{array}$ & $\begin{array}{l} \pm 20.1 \\
\pm 19.9 \\
\pm 11.4\end{array}$ & $\begin{array}{l}35.6 \% \\
41.6 \%\end{array}$ & $\begin{array}{l}69.0 \\
76.5\end{array}$ & 7.8 & $0.001 *$ \\
\hline $\begin{array}{l}\text { Experience in years } \\
\text { - }<5 \\
\text { - } 5- \\
\text { - } 10+\end{array}$ & $\begin{array}{l}76.8 \\
82.7 \\
61.5\end{array}$ & $\begin{array}{l} \pm 15.5 \\
\pm 17.3 \\
\pm 29.0\end{array}$ & $\begin{array}{l}40.0 \% \\
43.0 \% \\
32.0 \%\end{array}$ & $\begin{array}{l}79.5 \\
85.0 \\
48.0\end{array}$ & 3.9 & $0.026 *$ \\
\hline $\begin{array}{l}\text { Pre and in-service training } \\
\text { related to the GI endoscopy } \\
\text { procedure } \\
\text { - No } \\
\text { - Yes }\end{array}$ & $\begin{array}{l}67.5 \\
85.5\end{array}$ & $\begin{array}{l} \pm 20.9 \\
\pm 17.4\end{array}$ & $\begin{array}{l}35.1 \% \\
44.5 \%\end{array}$ & $\begin{array}{l}71.0 \\
85.0\end{array}$ & $\mathrm{t}=3.2$ & $0.003 *$ \\
\hline
\end{tabular}

F: One Way ANOVA

$\mathrm{t}$ : Students t- test for two independent samples

$* \mathrm{P}<0.05$ (significant) 
Table (4): Correlation between Safety Nursing Measures Scores during Upper GI Endoscopy Procedure and Nurses' Demographic Characteristics

\begin{tabular}{|c|c|c|c|c|c|c|}
\hline \multirow[t]{2}{*}{ Demographic characteristics } & \multicolumn{4}{|c|}{$\begin{array}{l}\text { Safety nursing measures during } \\
\text { upper GI endoscopy procedure } \\
\text { for the total items score }=(\mathbf{2 8 2})\end{array}$} & \multirow[t]{2}{*}{$\mathbf{F}$} & \multirow[t]{2}{*}{$\mathbf{P}$} \\
\hline & Mean & SD & Мea\% & Median & & \\
\hline $\begin{array}{l}\text { Settings } \\
\text { Endoscopy units of: } \\
\text { - University Hospitals } \\
\text { - Health insurance Hospital } \\
\text { - Private Hospitals and clinics } \\
\text { - Governmental Hospitals }\end{array}$ & $\begin{array}{l}143.1 \\
145.7 \\
177.5 \\
142.3\end{array}$ & $\begin{array}{l} \pm 33.5 \\
\pm 3.5 \\
\pm 23.0 \\
\pm 53.9\end{array}$ & $\begin{array}{l}50.7 \% \\
51.6 \% \\
62.9 \% \\
50.4 \%\end{array}$ & $\begin{array}{l}146.0 \\
145.5 \\
166.0 \\
158.0\end{array}$ & 4.1 & $0.011 *$ \\
\hline $\begin{array}{l}\text { level of education } \\
\text { - Nursing Diploma } \\
\text { - Technical institute of } \\
\text { nursing } \\
\text { - Bachelor }\end{array}$ & $\begin{array}{l}147.7 \\
184.8 \\
180.1\end{array}$ & $\begin{array}{l} \pm 35.7 \\
\pm 22.3 \\
\pm 26.7\end{array}$ & $\begin{array}{l}52.3 \% \\
65.5 \%\end{array}$ & $\begin{array}{l}156.0 \\
185.5 \\
193.0\end{array}$ & 4.9 & $0.012 *$ \\
\hline $\begin{array}{l}\text { Experience in years } \\
\text { - }<5 \\
\text { - } 5- \\
\text { - } 10+\end{array}$ & $\begin{array}{l}168.0 \\
160.6 \\
131.1\end{array}$ & $\begin{array}{l} \pm 24.2 \\
\pm 37.7 \\
\pm 42.6\end{array}$ & $\begin{array}{l}59.5 \% \\
56.9 \% \\
46.4 \%\end{array}$ & $\begin{array}{l}163.0 \\
156.0 \\
121.0\end{array}$ & 5.3 & $0.008 *$ \\
\hline $\begin{array}{l}\text { Pre and in-service training } \\
\text { related to the GI endoscopy } \\
\text { procedure } \\
\text { - No } \\
\text { - Yes }\end{array}$ & $\begin{array}{l}144.1 \\
157.8\end{array}$ & $\begin{array}{l} \pm 36.8 \\
\pm 37.5\end{array}$ & $\begin{array}{l}51.0 \% \\
55.9 \%\end{array}$ & $\begin{array}{l}150.0 \\
160.0\end{array}$ & $\mathrm{t}=3.4$ & $0.001 *$ \\
\hline
\end{tabular}

F: One Way ANOVA

$\mathrm{t}$ : Students t- test for two independent samples

$* \mathrm{P}<0.05$ (significant) 
Table (5): Correlation between Safety Nursing Measures Scores after Upper GI Endoscopy Procedure and Nurses' Demographic Characteristics

\begin{tabular}{|c|c|c|c|c|c|c|}
\hline \multirow[t]{2}{*}{ Demographic characteristics } & \multicolumn{4}{|c|}{$\begin{array}{l}\text { Safety nursing measures after } \\
\text { upper GI endoscopy procedure } \\
\text { for the total items score }=(\mathbf{1 1 4})\end{array}$} & \multirow[t]{2}{*}{$\mathbf{F}$} & \multirow[t]{2}{*}{$\mathbf{P}$} \\
\hline & Mean & SD & Мea\% & Median & & \\
\hline $\begin{array}{l}\text { Settings } \\
\text { Endoscopy units of: } \\
\text { - University Hospitals } \\
\text { - Health insurance Hospital } \\
\text { - Private Hospitals and clinics } \\
\text { - Governmental Hospitals }\end{array}$ & $\begin{array}{l}38.7 \\
34.9 \\
40.3 \\
29.9\end{array}$ & $\begin{array}{l} \pm 9.4 \\
\pm 1.3 \\
\pm 5.3 \\
\pm 4.4\end{array}$ & $\begin{array}{l}33.9 \% \\
30.6 \% \\
35.3 \% \\
26.2 \%\end{array}$ & $\begin{array}{l}37.0 \\
34.0 \\
39.0 \\
30.0\end{array}$ & 4.5 & $0.003 *$ \\
\hline $\begin{array}{l}\text { level of education } \\
\text { - Nursing Diploma } \\
\text { - Technical institute of } \\
\text { nursing } \\
\text { - Bachelor }\end{array}$ & $\begin{array}{l}36.5 \\
37.3 \\
44.8\end{array}$ & $\begin{array}{l} \pm 6.6 \\
\pm 3.9 \\
\pm 8.9\end{array}$ & $\begin{array}{l}32.0 \% \\
32.7 \% \\
39.2 \%\end{array}$ & $\begin{array}{l}36.0 \\
36.0 \\
47.0\end{array}$ & 5.2 & $0.009 *$ \\
\hline $\begin{array}{l}\text { Experience in years } \\
\text { - }<5 \\
\text { - } 5- \\
\text { - } 10+\end{array}$ & $\begin{array}{l}37.8 \\
40.5 \\
36.2\end{array}$ & $\begin{array}{r} \pm 4.9 \\
\pm 7.4 \\
\pm 10.8\end{array}$ & $\begin{array}{l}33.1 \% \\
35.5 \% \\
31.7 \%\end{array}$ & $\begin{array}{l}37.5 \\
38.0 \\
33.0\end{array}$ & 1.1 & 0.336 \\
\hline $\begin{array}{l}\text { Pre and in-service training } \\
\text { related to the GI endoscopy } \\
\text { procedure } \\
\text { - No } \\
\text { - Yes }\end{array}$ & $\begin{array}{l}36.3 \\
41.0\end{array}$ & $\begin{array}{l} \pm 6.6 \\
\pm 8.0\end{array}$ & $\begin{array}{l}31.8 \% \\
35.9 \%\end{array}$ & $\begin{array}{l}35.0 \\
40.0\end{array}$ & $\mathrm{t}=\mathbf{2 . 3}$ & $0.031^{*}$ \\
\hline
\end{tabular}

F: One Way ANOVA

$\mathrm{t}$ : Students t- test for two independent samples

$* \mathrm{P}<0.05$ (significant) 


\section{References}

1. Pascu o. Gastrointestinal Endoscopy. Croatia: Masa Vidovic, 2011; 9-15. Available at: http://www.intechopen.com Retrieved on: 27 Dec 2011.

2. Wallace M. Upper GI Endoscopy. Los Angeles: Clearinghouse, 2009; 22-5. Available at: http://digestive.niddk.nih.gov/ Retrieved on: 7 Jan 2012.

3. American Society for Gastrointestinal Endoscopy (ASGE). Ensuring the Safety of Your Endoscopic Procedure. 2010; 1-2. Available at: http://www.officite.com/.../pdfs/ensurin g-the-safety-of-yo. Retrieved on: 12 Jan 2012.

4. The Alfred Referral Guidelines. Indications for upper gastrointestinal endoscopy. 2011. Available at http://www.alfredhealth.org.au/Assets/F iles/GP_Referral_Endoscopy.pdf.

Retrieved on: April 2012.

5. World Alliance for Patient Safety:Forward Programme. Available at:

http://www.who.int/patientsafety/world alliance/en. Retrieved on: 15 Jan 2012.

6. British Society of Gastroenterology (BSG). Complications of Gastrointestinal Endoscopy; Guidelines in Gastroenterology. 2006; 31-4. Available at: http://www.health.bcu.ac.uk/webmodul es/gm607Z. Retrieved on: 20 Jan 2012.

7. Alfredsdottir H, Bjornsdottir K. Nursing and patient safety in the operating room. Journal of Advanced Nursing, 2008; 61(1), 29-37.

8. What Exactly Is Patient Safety: Available at: http://www.ahrq.gov/.../Advances-
Emanuel-Berwick 110. Retrieved on: 25 Jan 2012.

9. Francois J. Quality Control in Endoscopy Unit: Safety Considerations for the Patient. Available at: www.intechopen.com/download/pdf/14 838. Retrieved on: 10 Feb 2012.

10. The Endoscopy Unit and Staff. Available at: http://ebookbrowse.com/1405159022pdf-d104044416. Retrieved on: 10 May 2012.

11. Aspden P, Corrigan J, Wolcott J. Patient safety: achieving a new standard for care. Washington, National Academies Press; 2004.

12. Upper Gastrointestinal Endoscopy Procedure: Diagnostic Indications. 2010. Available at: http://www.tandurust.com/digestivedisorders/upper-gi-endoscopyprocedure.html. Retrieved on: 10 May 2012.

13. David J. Measuring the quality of endoscopy. The American Society for Gastrointestinal Endoscopy and the American College of Gastroenterology. 2006; 63(4): 23-7. Retrieved on: June 2012 .

14. Verschuur S, Ernst J, Kuipers M. Nurses working in GI and endoscopic practice. The American Society for Gastrointestinal Endoscopy.2007; 65, (3): 469-478. Available at: http://camerapil.eu/verpleegkundig/docu menten/Gastrointest\%20Endosc\%200407\%20Verschuur.pdf. Retrieved on: May 2012.

15. Gastrointestinal endoscopy. Available at:

http://www.emedicinehealth.com/gastro intestinal endoscopy/article em.htm. Retrieved on: Feb 2012. 
16. Spaner SH, Warnock G. A Brief history of endoscopy, laparoscopy, and laparoscopic surgery. Journal of Laparoendoscopic \& Advanced Surgical Techniques. December 1997; 7(6): 369373. Available at: http://online.liebertpub.com/doi/abs/10. 1089/lap.1997.7.369? Retrieved on: 10 Feb 2012.

17. Sivak M. Gastrointestinal endoscopy: past and future. An International Journal of Gastroenterology and Hepatology; 2006; 55 (8): 1061-1064. Available at: http://www.ncbi.nlm.nih.gov/pmc/articl es/PMC1856274/. Retrieved on: July 2012.

18. Hirschowitz I, Curtiss L, Peters C. Demonstration of a new gastroscope, the "fiberscope." The American Journal of Gastroenterology; 1958; 35(22): 509.

19. Future of endoscope. Olympus History Available at: http://www.olympusglobal.com/en/corc/history/story/endo/f uture/index.html. Retrieved on: July 2012.

20. Granz R. The development and the implementation of new endoscopic technology: what are the challenges? The American Society for Gastrointestinal Endoscopy; 2004; 6(3): 592-8. Retrieved on: May 2012.

21. Herman Miller for health care. Endoscopy: Planning Specialty Outpatient Surgery Departments. Zeeland: Michigan, 2000, P.1-6.

Available at:

http://www.workplaceresourcefla.com/d ocuments/wp_endo1000. Retrieved on: June 2012.

22. Hopkins H, Kapany N S. A flexible fiberscope, using static scanning. The American Journal of Gastroenterology Nature; 1954; 76(2): 864-9. Retrieved on: June 2012.
23. Santacroce L. Gastrointestinal endoscopy.2014. Available at : http://www.emedicinehealth.com/gastro intestinal_endoscopy/article_em.htm.

Retrieved on: June 2012.

24. Kandil A. Infection control measures for patients undergoing GIT endoscopy, unpublished master thesis, Faculty of Nursing. University of Alexandria, 2004.

25. Gaiso M. A visit to endoscopy clinics. 2003; 5(1):1-3. In Kandil A, Infection control measures for patients undergoing GIT endoscopy, unpublished master thesis, Faculty of Nursing. University of Alexandria, 2004.

26. Hookey L, Armstrong D, Enns R. Summary of guidelines for infection prevention and control for flexible gastrointestinal endoscopy. Canadian Journal of Gastroenterology. Jun 2013; 27(6): 347-350. Available at: http://www.ncbi.nlm.nih.gov/pmc/articl es/PMC3684370/ Retrieved on: June 2012.

27. Bradley J. Catalone M. Storing endoscopes: How long is too long? Scientific exploration casts doubt on sacred cow traditions. 2010 Available at:

http://www.hpnonline.com/inside/201011/1011-Endo-storage.html. Retrieved on: Jan 2012.

28. Muscarella L. The Safe Storage of Gastrointestinal Endoscopes.2013 Available at: http://endoscopereprocessing.com/2013/ 01/an-event-related-paradigm-appliedto-the-storage-of-flexible-endoscopes/. Retrieved on: Jan 2012.

29. Mahajan L, Wyllie R. The effects of a psychological preparation program on anxiety in children and adolescents undergoing gastrointestinal endoscopy. Journal of Pediatric Gastroenterology \& 
Nutrition. August 2002 ; 27( 2): 161165. Available at: http://journals.lww.com/jpgn/Abstract/1 998/08000/The_Effects_of_a_Psycholo gical Preparation_Program.6.aspx. Retrieved on: April 2013.

30. Kopfer M, McGovern M, transmission of HIV via a needle stick injury. American association for occupational health nurse journal; 2003; 4 (16): 21822.

31. Mokhter E. Assessment of nurses' knowledge and performance regarding the nursing care given to chronic renal failure patient undergoing maintenance hemodialysis, unpublished Master Thesis, Faculty of Nursing. Cairo University, 2008.
32. Hadded N, impact of educational program on nurses' knowledge of general practioner, annual of Saudi medicine; 2002; 17(8): 5:10.

33. Duffel W, Merry R. staff development. Nursing mirrors. American Association of Critical Care Nurses; 1993; 159 (23):315-23. Retrieved on: May 2013

34. Guilbert J, educational hand book of health personal. $6^{\text {th }}$ ed. London, Mosby Company, 2000. Retrieved on July 2013

35. Streubert J, Carpenter R. qualitative research in nursing, advanced the humanistic imperative, $3^{\text {rd }}$ ed, Philadelphia: Lippincott William walking company, 2003. Retrieved on: Aug 2013. 
Safety Measures for Patients Undergoing Upper GIT Endoscopy 